\title{
Discussion on SME Financial Management Problems and Countermeasures
}

\author{
Yang Xuhui ${ }^{1}$ \\ School of Economics and Management \\ Beijing JiaoTong University \\ Beijing, P.R.China \\ e-mail: 10178011@qq.com
}

\author{
Zhang Ruoxi ${ }^{1}$ \\ School of Economics and Management \\ Beijing JiaoTong University \\ Beijing, P.R.China \\ e-mail: zrx1028@126.com
}

\begin{abstract}
The paper analyzes the status of the financial management of SME based on the depiction of what to define SME, it can As to this, it gives the field research towards some representative SME financial management status, in order to find out where problems exist and dissect what the enterprise take counter measures and effect. And finally, we focus on summing up the widespread problems about the financial management of SME and giving specific solutions, measures and suggestions to develop the financial management of SME in China.
\end{abstract}

\section{Keywords-SME, Financial management, Countermeasures}

\section{INTRODUCTION}

As an important part in the development of the national economy, SME accounted for $99.6 \%$ of the total number of enterprises in China, and had a great impact on promoting China's economic and social development. Especially at present, SME is playing an increasingly important role in ensuring appropriate growth of the national economy, easing the employment pressure, rejuvenating the country through science and education and optimizing the economic structure.

Because of its small assets scale, SME is not strong enough to withstand market risks. The financial system is not perfect and the financial management lags behind, and also by changes in macroeconomic environment and institutional impact, most SME in China is relatively short-lived. Financial management problems are particularly prominent, which constraints and determines the development of small and medium-sized enterprises. Practice has proved that financial management is the core of enterprise management and scientific and financial management is extremely important for the survival and development of enterprises. ${ }^{[1]}$

\section{SME FINANCIAL MANAGEMENT PRESENT SITUATION AND THE CASE ANALYSIS}

\section{A. Financial Management Analysis of SME}

The enterprise's financial management has the extremely important position in the modern enterprise: first of all, the management of the capital movement is the center of the modern enterprise management. The effectiveness of financial management will directly affect the enterprise's overall benefit. Second, whether the enterprise's capital turnover is smooth, reasonable and effective determines the survival and development of enterprises.
For financial management of SME in China, on the one hand, SME does not stress the core position of the financial management, but just take the traditional management thinking that financial management is equivalent to the production of economic management. Therefore, it did not play to the role of corporate financial management. On the other hand, due to the macro-economic system, as well as the impact of environmental change, the financial management of SME is affected at a certain extent potentially. For example, SME and large enterprises are in unfair competitive for policy reasons. SME development is influenced too much by the intervention of the administrative department of the local government industry, as well as financial management is influenced by the enterprises' leadership, and so on ${ }^{[13-21]}$

\section{B. The case analysis of SME financial management}

The author deeply researched a small and medium-sized enterprise specializing in doors and Windows production sales in Beijing and analyzed the problems of financial management. The author tried to put forward some concrete solutions and measures, hoping that offer some useful references.

\section{1) General situation of enterprise}

The enterprise was built in 1996, turned into a small and medium-sized private enterprise from a state-owned enterprise. It has large scale and has the certain representation in the same industry in Beijing. The enterprise has 3.8 million yuan of registered capital and the production workshop covers more than 1500 square meters, with 3 million yuan in fixed assets and 102 employees including 13 managerial personnel and 10 engineering and technical personnel.

The enterprise has offices, finance department, production department, sales department, security environmental protection department, QC department, technical department, reference room. With three production workshops: plastic production workshop, color coated workshop and security doors workshop. All departments of the management system have working system, procedures and post responsibility system.

After years of efforts, the company has established a good reputation between the dealers and the customers and maintained a growing trend. But with the enlargement of enterprise in scale, problems appear in the enterprise 
management and financial management such as large scale, imperfect financial management, and unhealthy anti-risk ability and so on.

2) Analysis of the status and problems

Now, according to the investigation data of the enterprise, the author would analyze the present situation of the financial management and find out the problems.

a) Financial management system is not detailed

The enterprise is large in scale but lack a detailed financial management system. There is no clear hierarchy system in financial management personnel and employees' wages. There is also no detailed evaluation, rewards and punishment system. The management model is old and not standard. In addition, there are many problems such as: accountings are relatives of management; no distinguish of accounts, cashier, which easily led to unclear responsibility.

b) The structure of current assets is unreasonable and assets turnover is low

As TABLE 2 shows, the average current assets accounted for $59.7 \%$ of total assets and total of accounts receivable and inventory accounted for $93.7 \%$ of the current assets in the structure of current assets. The structure of current assets is badly unreasonable in which accounts receivable and inventory accounted most. The neglect of accounts receivable led to bad debts as money cannot be recovered in time. All above increased the burden and reduced the profit of the enterprise.

TABLE 2. the STRUCTURE of CURRENT ASSESTS of the CASE ENTERPRISE

\begin{tabular}{|l|l|l|}
\hline Assets & Average(ten thousand Yuan) & Percentage\% \\
\hline Accounts receivable & $360(343+377) / 2$ & $70.1 \%$ \\
\hline Monetary fund & $27.5(23+32) / 2$ & $5.4 \%$ \\
\hline Notes receivable & $2.75(3.7+1.8) / 2$ & $0.53 \%$ \\
\hline Prepayments & $1.9(1.6+2.2) / 2$ & \\
\hline Inventory & $121.4(114.8+128) / 2$ & $23.6 \%$ \\
\hline
\end{tabular}

\begin{tabular}{|l|l|l|}
\hline Total current assets & $513.5(480+547) / 2$ & $59.7 \%$ \\
\hline Total assets & $860(810+910) / 2$ & $100 \%$ \\
\hline
\end{tabular}

c) The cost system is not perfect

The enterprise's cost management system had no complete organization and working system. The responsibility system for cost management was implemented badly and it showed more random in expenses range, grade standard, cost forecasts and decisions, evaluation, analysis, and examination. Each fixed target was practiced while discussion. For example, production quota only determined the personnel workload with no evaluation index in material consumption per unit area, and that caused the waste of materials and increase of production cost.

\section{d) Poorly planning of financing management}

The enterprise had no detailed plan in fund management and lacked of accurate prediction of funds demand. The production and business operation activities restricted by the market were poorly planned. As the production plan was not sure, financial officers failed to predict the funds demand accurately and led financing not in place. At last, downtime seriously affected the economic benefit of the enterprise. In addition, unclear financing channels caused high cost of capital. As managers don't acknowledge ways to raise capital, they bought materials on credit, requested for advance to demand side and then borrowed from banks when facing cash flow difficulties, and it increased the burden of the enterprise.

\section{3) Countermeasures and results}

To solve problems existed in the financial management, the enterprise have listened to some professional advices: on the one hand, the enterprise should establish the modern and standardize management system in order to the long-term development; on the other hand, they should take some short-term reform measures. As a result, the enterprise has obtained the good achievement in financial management.

a) Formulate detailed system of salary levels and system of rewards and penalties. It's very important to the enterprises' financial management that standard written, strict system of salary level and system of rewards and penalties, especially to SME with high turnover rates.

b) Use the genuine management software. Select suitable management software for the enterprise to realize from basic cashier to the all-around management. Then, the enterprise ended up the state of decentralized management of products and financial staff could timely check the invoicing, receivable and accounts payable and costs so as to provide relative information to owner. 
c) Formulate financial system and training. Combined with the actual, professionals advise a series of financial management system, such as the expense system, commodity inventory method, etc. The duty of financial personnel regulations that the workload per financial personnel should complete per month and reports should be provided. Conduct training to related people to help them understand the financial management system and operate the control software skilled, instilling role of financial management and leading them to bring the control software into full play.

After the professionalization of the consultation, the enterprise has achieved good results. But the enterprise must take a series of long-term reform measures to follow development and growth, such as gradually establish a modern and standardize enterprise management; bring in professional managers, adopt the modern HR management and build atmosphere of teamwork; make full use and reasonable allocation of internal / external resource, further improve the efficiency and benefit and guard against business risks; further adopt advanced management methods and techniques.

\section{PROBLEMS AND COUNTERMEASURES OF SME FINANCIAL MANAGEMENT}

\section{A. Analysis of SME financial management problems}

The bad external operating environment of financial management of SME and they do not attach importance to financial management, therefore, there are many problems, now we see it from inside and outside ${ }^{[4]}$ :

\section{1) The external problems}

The main external problems faced by SME in the financial management is the small financing channels, high financing costs, financial difficulties that caused by the lack of follow-on funding, which restricts its development as the key issues.

It mainly performance in the following five aspects: First, there are discrimination on the bank credit policy. Not given due credit support to SME, financial institutions' loan to SME is basically limited to working capital loans, it's longterm development of the required capital is difficult to be satisfied. Second, there discrimination of ownership on the bank interest rate policy. The government and the central bank give more preferential interest rates to enterprises of the state-owned, while the private sector not been given. The floating range of the private sector is often higher than that of state-owned enterprises. Some financial institutions have also taken some irregularities, unauthorized or disguised improving lending rate of the private sector. These problems have increased the cost of financing for the private sector. Third, in terms of direct financing, capital markets focused on providing quality services for large enterprises. Management has seen using its' stock listed on the stock exchange as magic when large state-owned enterprises are in predicament. Management basically hold exclusionary attitude to the small and medium-sized private enterprises to enter the corporate bond market, stock issuance. Fourth, in terms of financial organizations, it lacks of financial institutions that could provide specialized services for the development of SME. Fifth, because of the disadvantage of small and medium-sized private enterprises in the market, and lacking of government support, so its natural ability to credit and own financing capacity is low, which contribute to the shortage of funds.

\section{2) The internal management issues}

Besides external inevitable problems, SME is limited by the scale and quality of personnel, and its internal management is the main problem.

a) Financial management level is not high.

SME has seen accounting as an information disclosure needs or means of accounting, rather than as a management tool. While accounting is keeping accounts, they often ignore the actual situation, and sometimes it will generate an error message, misleading policy makers, and managers often do not attach importance to it.

\section{b) The financial management system is imperfect}

Actually, some SME did not set up the books. In many enterprises there are many problems such as: accountings are relatives of management; no distinguish of accounts, cashier; financial management confusion and other issues.

c) The lack of the investment budget decision-making function of funding

Operators generally pay less attention to the capital plan and budget. SME behavior often shows a lack of long-term planning and decision-making, usually made by the operator by virtue of his own experience. At the same time due to the unsound organizational structure of SME and the low number of financial officers who generally are busy with the day-to-day financial work, so they don't have more energy to work in this area.

d) Lack of scientific asset management and weak control

SME generally do not have strict asset management system, there are much human effects on management. It performance in the following aspects: first, the lack of analysis of accounting information, and ignoring the analysis and use of accounting information. Second, the inventory is not in control, a large inventory takes up a lot of money, leading to capital sluggish and cash flow problems; Third, not strict control of receivables, resulting in a large number of difficult in recovery of funds, and they generally do not have a strict credit policy, and no powerful reminders accounts measures, which often cause a large number of bad debts; Fourth, cash management is lax, resulting in idle or insufficient funds; Fifth, adverse custody of assets, lack of perfect management of raw materials, semi-finished products, fixed assets which result in unable to check when things go wrong, and have to suffer a serious loss of assets. 


\section{B. Countermeasures and suggestions for SME financial management problems}

1) The Government needs to support the development of SME in the policy

As he competent authorities to support the development of SME, the government should improve financial services for SME, strengthen SME credit support, deepen the reform of commercial banks, and improve the system of financial enterprises. Commercial banks should be transformed into Modern financial enterprises that have capital adequacy, strict internal control, safe operations, good service. And select the good conditional state-owned commercial banks to implement the joint-stock reform, expedite the disposal of non-performing assets, get more capital, and create the conditions for listing, and cultivate a favorable credit environment. To solve the problem of weak social credit, the SME credit system should be established as soon as possible, and strengthen the credit culture. They should nurture entrepreneurs credit awareness, promote and publicize the concept of credit, and improve the relationship between banks and enterprises under the trustworthy environment.

2) Improve the corporate financial system and the understanding of financial management

The owner and managers of SME need to improve understanding of financial management, breakthrough thinking, and accept advanced scientific management ideas. Also they must enhance professional knowledge learning, and implement the concept of financial management in the business activities, and combine it with the actual development of financial management to explode a proper enterprise development mode. In terms of financial institutions set, it needs reform existing financial sector, set reasonable jobs of financial accounting and the related, the financial system should be feasible, such as job division and job rotation. Job rotation should go as time, successor should verify current accounts, in order to strengthen supervision. Corporate finance department should establish a sound financial management system in line with the requirements of enterprise development, which should be in accordance with the requirements of the current rules and regulations, and combined with the actual situation of the enterprise. SME should strengthen financial management, implement the accounting standards for Business Enterprises and the small business accounting standards, establish the system of internal accounting.

3) Strengthen the financial budget control and strictly control the financial decisions

The long-term goal of improving the budget system is to create a set of system that suits the actual situation of enterprises, which is combined with of the company's overall financial management and covered and connected with business objectives at all levels of the budget process; Corporate financial decisions mainly refers to the investment decision-making, and the investment responsibility system can be used.

First, the separation of incompatible duties system. Incompatible duties mutual separation of the control requires SME set reasonable financial accounting and related jobs, clear responsibilities permission to form a mutual checks and balances, in accordance with the principle of separation of incompatible duties. Incompatible duties include: authority to authorize the Business Manager, accounting records, property custody, inspection duties such as: the right to approve the procurement of personnel not directly engaged in procurement operations, personnel engaged in procurement operations shall not be engaged in the warehousing business.

Second, the authorization approved control system. authorization approved control system requires SME is clearly defined authorized to approve the scope of financial accounting and related work, authority, procedures, responsibilities, units within all levels of management must exercise their functions and powers within the scope of authority and responsibility, handling personnel must be within the scope of authority to transact business. Such as: procurement personnel must do the procurement within the approved amount of price, it needs examination and approval of the charge when the amount exceeds the approved one.

Third, form a team of project responsibilities, clear lines of responsibility and the purpose of assessment. The responsible person is responsible for project preparation, negotiation and implementation of the entire process control work, the responsibility of companies should assess it for the project feasibility study report economic indicators as a reference basis.

\section{4) Strengthen its own fund management}

First, make best to improve the efficiency in the use of funds. As working capital is needed to maintain the daily production and operation funds, and is closely related to the cash cycle of the business activities, the lack of working capital will directly affect corporate transactions.

Second, strengthen the management of inventories. The cost of inventories refers the cost of the total cost of the inventory, is all the expenses of the enterprise inventory. Currently, China's SME widespread has the trend of the dramatic increase in inventory cost. Sufficient inventory reserve is beneficial to reduce procurement costs and production costs, it can meet the needs of the production and operation, but the increase in inventories occupied the capital, and also caused by the increase in storage costs and management fees, however, insufficient inventory reserves shows the opposite. SME should adopt advanced inventory management methods. Economic purchase batch mode and advance orders model can be used in the procurement phase to figure out economic purchase batch and advance ordering time. The economic status of the stock can be measured by the inventory storage period of capital preservation and storage period of Poly in storage stage. Of course, due to 
differences in scale, small businesses should not copy the pattern of large enterprises, enterprise managers should be read in conjunction with the results of the scientific method, to make decision on inventory according to the actual situation and their own experience.

Third, strengthen the management of the accounts receivable. For SME is in a competitive industry, and in the face of fierce market competition, it is often eager to expand sales to capture the market, most of them to take a more flexible credit terms, so that the increase in sales revenue, so as the receivables. When SME implement easy sales policy, while credit management has lagged far behind, most of them did not develop credit management policies in line with their own characteristics, and the lack of incentive payments to customers and punitive measures in a time, the ability to assess the credit risk is also serious, the financial turmoil greater the risk of bad debts and receivables management costs, and also slows down the speed of recovery of cash, exacerbates the tensions of finance for SME. They should strengthen the management of accounts receivable, and strive to strengthen the assessment of credit research for credit customers, and regularly check existing receivables, make perfect repayment way, strictly control aging receivables. Properly treat bad debts, bad debts after obtaining conclusive evidence.

\section{CONCLUSION}

Through the above research on the theory and practice of SME, we can see that a lot of problems exist in the SME, especially confusion in financial management is the important factor restricting the development of SME in standardization, which is certainly the responsibility of managers who do not attach importance to, but the SME themselves should take more responsibility.

Recommendations of the financial management of SME in this paper are just some general advice; SME should establish a financial management system in line with their own development based on its own operating characteristics, at the same time they should make best of its operating flexibility as constantly adjust themselves according to changes in business strategy. I believe that in the course of China's development, the applications and improvement of SME financial management, will promote the SME to achieve a breakthrough development.

\section{REFERENCES}

[1] Chen Ruiwang. Played theRole of the Financial Management of SME Thematic Studies [D]. Kunming: Kunming University of Science and Technology, 2007

[2]Liu Rongli. On Enterprise Financial Management [J]. Assets and Finances in Administration and Institution, 2012, (7)

[3]Huang Huixin. China's SME Financial Management Mode [D]. Guangzhou: Guangdong University of Economics and Management College, 2008

[4] Fu Zhuo. China's SME Financial Management Mode [D]. Xiamen: Xiamen University, 2001

[5]Tian Fen. the Economic and Social Impact of the Development Situations of SME[J] Chinese Statistics, 2010, (12), $53 \sim 55$

[6]Feng Yi, Zhang Yurong. Research on SME Financial Management Situations [J]. Peoples Forum, 2011, (8)

[7]Zhao Chao.Comparative Study of SME [J]. Lanzhou Journal, 2001, (5)

[8] Zhong Shengcheng.Management Situations and the Main Problems of SME in China [J]. Wuhan Technical Institutes Journal, 2000, (4)

[9]Lu Jiayi.Financial Management[M] .Beijing: Tsinghua University Press, 2001

[10]QinZhimin, NiuYanXiu.Financial Management [M].Hei Longjiang: Northeast China University of Finance and Economics Press, 2009

[11]Li Dawu.Financing Difficulties of SME Cause Analysis and Strategic Choice [J]. Financial Research, 2001, (10)

[12]Chen Haiyi.SME Financial Management Problems and Their Countermeasures[J].Journal of Economy and Management Research, 2004, (6).

[13]Gong Yiping.the Problems in the Financial Management of SME and Countermeasures[J]. Accounting Research, 2005, (3)

[14]Zhang Ruijie. Discussion on the Certain Problems of China's SME financial management [J].Journal of Inner Mongolia Science and Technology and Economy, 2006, (19)

[15]Guo Yinhua.SME Financial Management Problems and Countermeasures [J]. Accounting Research, 2006, (3)

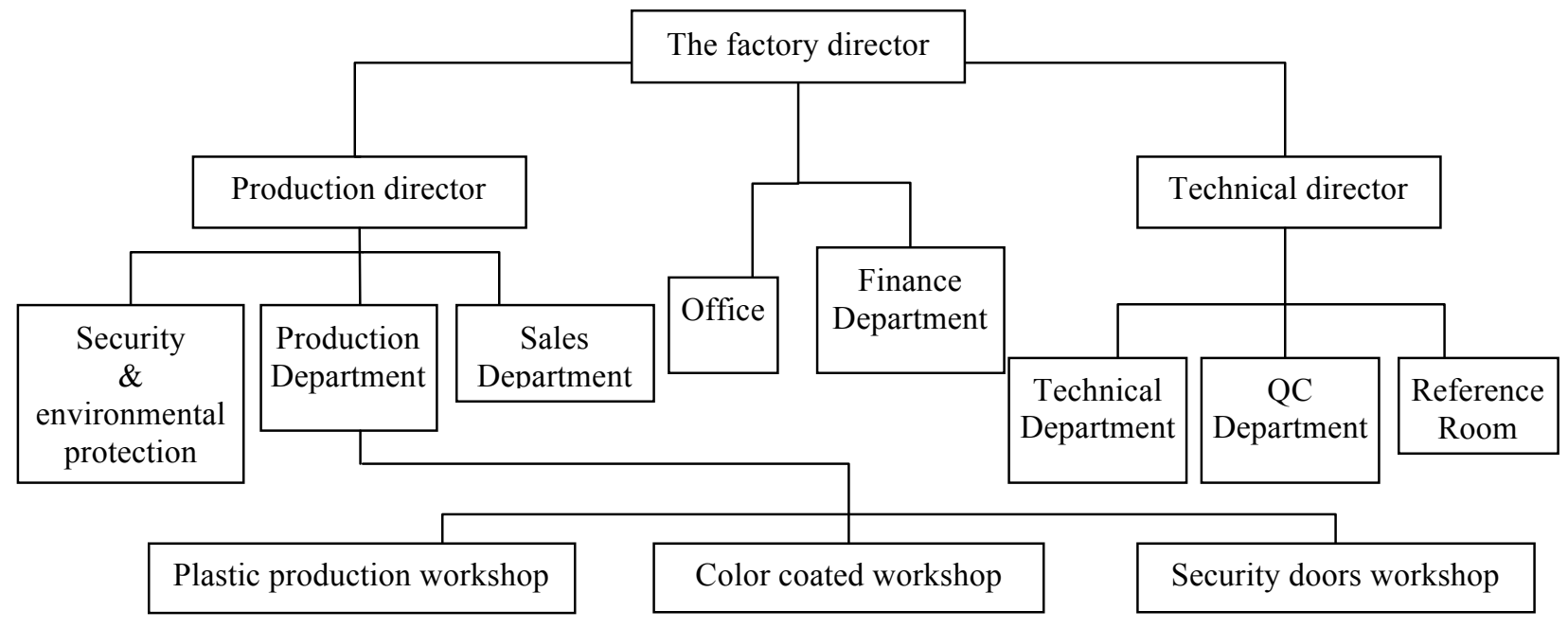

Figure 1. the Management architecture diagram of the case enterprise 
